\title{
As Representações Sociais da Maternidade para Mães de Filhos/as com Deficiência
}

\author{
The Social Representations of Maternity for Mothers of Children with Disabilities
}

Las Representaciones Sociales de la Maternidad para las Madres de Hijos con Discapacidad

\author{
Kelly Nunes Crisostomo ${ }^{1}$ \\ Fabiana Regina da Silva Grossi \\ Rafaela dos Santos Souza \\ Faculdade São Francisco de Barreiras
}

\begin{abstract}
Resumo
A descoberta na gravidez de um/a filho/a com alguma deficiência pode trazer efeitos principalmente sobre os sentimentos das mães. Diante disso, objetivou-se analisar as representações da maternidade para mães de filhos/as com deficiência de uma escola pública no município de Barreiras, BA. Tratase de uma pesquisa qualitativa, descritiva e exploratória. O instrumento utilizado foi a entrevista semiestruturada, e a coleta de dados foi realizada com 14 mães, sendo utilizada a teoria das Representações Sociais para estudo dos dados obtidos. Identificou-se que existe uma busca pelo filho/a "ideal", e a chegada de uma criança com deficiência gera sentimentos negativos, tais como choque, medo e tristeza. Além disso, elas ainda precisam lidar com as dificuldades em uma sociedade preconceituosa. Portanto deve-se pensar em intervenções e suporte psicológico a fim de diminuir os obstáculos encontrados, bem como promover melhor qualidade de vida para essas mulheres desde o diagnóstico da deficiência da criança.
\end{abstract}

Palavras-chave: representações sociais, maternidade, filhos/as com deficiência

\begin{abstract}
The discovery in pregnancy of a child with a disability may have effects mainly on the feelings of the mothers. The purpose of this study was to analyze the representations of motherhood for mothers of children with disabilities in a public school in the municipality of Barreiras, BA. This is a qualitative, descriptive and exploratory research. The instrument used was the semistructured interview and data collection was performed with 14 mothers, and the Social Representations theory was used to study the data obtained. It was identified that there is a search for the "ideal" child and the arrival of a child with a disability generates negative feelings, such as shock, fear and sadness. Moreover, they still have to deal with the difficulties in a prejudiced society. Therefore, interventions and psychological support should be considered in order to reduce the obstacles encountered, as well as to promote a better quality of life for these women since the diagnosis of the child's disability.
\end{abstract}

Keywords: social representations, maternity, children with disabilities

\section{Resumen}

El descubrimiento en el embarazo de un hijo con alguna deficiencia puede traer efectos principalmente sobre los sentimientos de las madres. Ante ello, se objetivó analizar las representaciones de la maternidad para madres de hijos con discapacidad de una escuela pública en el municipio de Barreiras, BA. Se trata de una investigación cualitativa, descriptiva y exploratoria. El instrumento utilizado fue a la entrevista semiestructurada y la recolección de datos fue realizada con 14 madres, siendo utilizada la teoría de las Representaciones Sociales para el estudio de los datos obtenidos. Se identificó que existe una búsqueda por el hijo "ideal” y la llegada de un niño con discapacidad genera sentimientos negativos, tales como shock, miedo y tristeza. Además, las mismas todavía tienen que lidiar con las dificultades en una sociedad preconcebida. Por lo tanto, se debe pensar en intervenciones y soporte psicológico a fin de disminuir los obstáculos encontrados, así como promover mejor calidad de vida para esas mujeres desde el diagnóstico de la discapacidad del niño.

Palabras clave: representaciones sociales, maternidade, hijos con discapacidad

\footnotetext{
${ }^{1}$ Endereço de contato: BR 135 Km 01 2341, Rua Boa Sorte, BA, 47800-970. Tel. (77) 3613-8800. E-mail: kellynunes_knc@hotmail.com.br
} 


\section{Introdução}

Ainda hoje é possível perceber uma pressão social pela busca de um filho idealizado, aquele que está dentro de um padrão socialmente aceito, de forma que, quando essas expectativas não são supridas, ocorre um grande impacto, tornando um desafio desconstruir esse modelo padronizado do filho/a ideal que é reforçado pela sociedade. A descoberta na gravidez de um filho/a com alguma deficiência pode trazer efeitos principalmente sobre os sentimentos das mães, levando em conta que é sobre a figura da mulher que acarreta maiores cobranças na relação familiar do cuidado com os/as filhos/as (Brunhara \& Petean, 1999).

Entende-se a criança com deficiência como um indivíduo que oferece alguma limitação como consequência de sua condição específica; porém as interações estabelecidas socialmente, com influências culturais, psicossocial, política e econômica é o que determinará a deficiência, e não a sua especificidade (Silva, 2011). Nesse sentido, deve-se salientar a importância da família e, em especial, das mães de filhos/as com deficiência nesse processo.

Uma das preocupações mais frequentes é de como a sociedade vai tratar uma criança com deficiência, como também das dificuldades da inserção social desta e das mudanças nas rotinas, pois muitas mães acabam abrindo mão da sua carreira profissional para cuidar da criança. Com isso, há uma superação quando essa criança deixa de ser vista somente pelas suas limitações e passa a ser compreendida como ser integral, possibilitando novos olhares para a deficiência (Batista \& França, 2007; Milbrath, Cecagno, Soares, Amestoy, \& Siqueira, 2008; Souza \& Boemer, 2003).

Conforme Amiralian (2003), o crescente interesse de psicólogos/as na busca por desenvolver e explorar a problemática da deficiência tem colaborado para debates importantes a respeito do conceito de deficiência e com relação a outros aspectos referentes ao desenvolvimento, aprendizagem e intervenção. Isso mostra a necessidade de ouvir as mães de filhos/as com deficiência, visto que a literatura afirma que essas mães expressam reações de tristeza, choque, resignação e de negação com a descoberta e chegada de um/a filho/a com alguma necessidade específica no núcleo familiar, sentindo-se responsáveis em cuidar da criança.

Nesse sentido, buscar compreender as representações sociais que as mães de crianças com deficiência têm sobre os/as filhos/as, como lidam com esse processo de aceitação e as dificuldades enfrentadas por essas mães, é essencial. Existe uma preocupação exclusiva com as crianças com deficiência, esquecendo os sentimentos das mães, suas percepções, frustrações e dificuldades, que poderão influenciar nos comportamentos, ajustamento social e desenvolvimento dos/as filhos/as, se não forem trabalhadas.

Portanto este estudo busca analisar as representações sociais da maternidade para mães de filhos/as com deficiência de uma escola pública que oferece Atendimento Educacional Especializado (AEE) para crianças com deficiência múltipla e intelectual do município de Barreiras, BA, levando em consideração os significados e as características subjetivas que estão fundamentados e apontando os comportamentos e atitudes frente às crianças com deficiência, com intuito de trazer aspectos afetivos, psicossociais e as dificuldades que cercam a temática. 


\section{Representações Sociais}

O termo Representações Sociais foi cunhado em 1961 pelo psicólogo social francês Serge Moscovici e, a partir dele, essa teoria vem sendo abordada por diversos autores importantes. Trata-se de uma teoria que busca explicar os fenômenos, tornando espaços para estudos psicossociológicos (Sá, 2004).

Segundo Moscovici (2007), a representação social está relacionada com a intenção de classificar as coisas ou os indivíduos, isto ocorre em uma tentativa de descrever seus sentimentos e ações. Essa teoria verifica as representações que se têm sobre os objetos, pessoas e situações e estuda o indivíduo nas suas relações com ambiente, ou seja, foca-se nas relações humanas. É importante salientar também que a teoria das Representações Sociais é uma forma sociológica de Psicologia Social, que é considerada uma área da psicologia que estuda as interações entre o indivíduo e a sociedade e, a partir dessa relação, é que ele se constrói (Farr, 1995).

Nessa perspectiva, Ferreira, Neves, Siqueira, e Barbosa (2013) afirmam que existe uma grande relação entre representações sociais e saúde, especialmente no contexto socioeducativo, no qual se articulam os fenômenos coletivos e individuais. A partir da pesquisa socioeducativa em saúde, pode-se compreender e discutir a dimensão social dos problemas do indivíduo e sociedade. Logo, é oportuno ressaltar que a influência das representações sociais também se apresenta como determinante na concepção da maternidade, assim como a influência de padrões culturais, crenças e valores, a qual se inscreve num momento historicamente construído, dentro da dinâmica da sociedade.

\section{A Mulher e sua Relação com a Maternidade}

As mulheres têm se inserido constante e progressivamente nos âmbitos sociais, antes consideradas de esferas exclusivamente masculina. Essas modificações têm refletido nos significados da identidade feminina e nas relações de gênero, no que diz respeito à promoção de reposicionamento e redefinição de papeis e identidades. Entretanto os papéis femininos apresentam diferentes configurações em diferentes setores da vida em sociedade, principalmente nos domínios do trabalho e na criação dos/as filhos/as que deixam marcas nas experiências da maternidade (Almeida, 1987).

Vale ressaltar que, até então, a mulher era associada ao âmbito familiar, competindo-lhe função essencialmente de procriação. Contudo a concepção do ser feminino atualmente ainda significa assumir um papel de mãe amorosa e sempre presente no lar, impregnando a noção de maternidade ideal, no qual as mulheres estão predeterminadas para os cuidados dos/as filhos/as enquanto que os homens pertencem às vivências do cotidiano social, tidas como mais essenciais (Coutinho \& Menandro, 2009).

Mesmo com tantas mudanças, a mulher ainda é considerada a responsável pelos cuidados dos/as filhos/as, deixando em último plano suas realizações profissionais e pessoais. Nos dias de hoje, uma família com filhos/as criados/as e cuidados/as por pai e mãe é vista como uma exceção (Coutinho \& Menandro, 2009).

Conforme Begossi (2003), a mulher já é ensinada a cuidar de um bebê na infância, quando brinca de ser mãe com as bonecas e aprende a partir das suas vivências com os outros. 
Essas experiências dos cuidados com o bebê e também os hábitos e valores sociais que são impostos à figura de ser menina e logo após mulher, que não estão relacionados apenas aos aspectos concretos, mas também emocionais, possibilita que a mãe saiba identificar quais as necessidades da criança.

De acordo Maldonado (1997), a gravidez faz parte do desenvolvimento natural do ser humano, um processo de transição que envolve reestruturações e reajustamento em diversas dimensões. Contudo a chegada de um novo membro na família sempre causa uma grande expectativa e grandes preparações que dão início já na gestação, quando a mãe cria sentimentos e pensamentos em relação à chegada desse bebê, que muitas vezes vem acompanhado da idealização da figura do/a filho/a belo/a e com saúde, que marcam a maternidade.

\section{Luto do/a Filho/a Ideal}

Durante a gravidez, as mães e as famílias, geralmente, já idealizam seus bebês com relação ao sexo, personalidade, aparência que são formados por impressões de suas experiências de vida. Segundo Begossi (2003), no período de gestação, a mulher vivencia sentimentos de ansiedade e medo de que o bebê possa nascer morto, prematuro ou com alguma deficiência.

Se esse filho tão imaginado frustra todas as expectativas, causa um choque na mãe, pois o plano da fantasia até então era preenchido por um/a filho/a idealizado/a que passa a ser substituído por um ser real "imperfeito". Não é de se surpreender se os pais, ao receberem uma criança com deficiência, reajam como se estivesse perdido um ente querido e iniciem um processo de luto, visto que, até então, não estavam preparados para essa chegada (Rolim \& Canavarro, 2001).

Conforme Rolim e Canavarro (2001), o processo de luto do/a filho/a idealizado/saudável é semelhante ao processo de luto de qualquer outra perda que pode gerar respostas emocionais específicas como respostas afetivas (sentimentos e emoções como culpa, tristeza, solidão ou raiva), comportamentais (choro, agitação, fadiga), cognitivas (baixa autoestima, falta de concentração ou memória) e fisiológicas (insônias, perda de apetite, queixas somáticas). Para Maldonado (1997), a angústia de dar à luz uma criança com deficiência pode ter origem na infância, quando é formada uma imagem básica da criança com outras pessoas ruins ou boas. Esses sentimentos, muitas vezes, manifestam-se por meio do "castigo" de ter um/a filho/a com deficiência.

Quando a mulher recebe o diagnóstico de um/a filho/a, costuma reagir de diferentes maneiras, dependendo das suas características próprias e das influências socioculturais que recebem. As reações podem evoluir para diferentes estágios, muitas vezes decorrentes da vergonha ou medo da rejeição social que podem propiciar o isolamento social (Silva, 2011).

\section{Método}

Trata-se de um estudo do tipo aplicado, transversal, descritivo e exploratório. De acordo com Cervo e Bervian (2002), a pesquisa descritiva busca estudar um fenômeno sem manipulá-los, procura descrever as características desse fenômeno, a frequência em que ocorre e sua natureza. Os autores citados ressaltam ainda que os estudos exploratórios têm como finalidade realizar descrições indispensáveis sobre o fenômeno estudado, exigindo um conhecimento prévio sobre o assunto, com intuito de descobrir a conexão entre os elementos 
que o constituem. Além disso, neste estudo foi utilizado o método qualitativo que, conforme Richardson (1989), não está relacionado a números, isto é, não se aplica um instrumento estático para analisar o fenômeno. Nesse método, as informações sobre os fenômenos são mais profundas, para descrever detalhadamente os fatos estudados (Minayo, 1998).

A pesquisa se desenvolveu em uma escola municipal localizada no município de Barreiras, Bahia. Trata-se de uma escola de ensino regular que atende crianças do maternal ao $5^{\circ}$ ano do ensino fundamental; além disso, oferece Atendimento Educacional Especializado (AEE) para pessoas com deficiência múltipla e intelectual. Esse local dispõe de uma sala de recursos multifuncionais para o Atendimento Educacional Especializado com cursos para os/as alunos/as com deficiência, sendo que a pesquisa foi realizada com as mães dessas crianças que estavam matriculadas na escola em questão, especificamente na sala de recursos (AEE).

A coleta de dados se fez no período de novembro de 2016 a março de 2017, e sua aplicação ocorreu mediante autorização do Comitê de Ética em Pesquisa Cientifica com Seres Humanos (CEP) da Faculdade São Francisco de Barreiras (FASB) sob o parecer no 1.761.050, como também o Termo de Consentimento Livre e Esclarecido (TCLE) seguiu os preceitos da resolução no 466/12 do Conselho Nacional de Saúde do Ministério da Saúde do Brasil.

A coleta de dados foi realizada com 14 mães dos alunos/as com deficiência através de uma entrevista semiestruturada. A primeira parte da entrevista referiu-se ao questionário sociodemográfico e econômico e, em seguida, foram realizadas as perguntas referentes ao tema central da pesquisa, elaboradas pelas autoras e que ocorreram individualmente, com dias e horários distintos, para que as entrevistadas ficassem sozinhas com as pesquisadoras, garantindo o sigilo das informações. Utilizou-se da gravação de áudio e, posteriormente, da transcrição para compreensão de seu conteúdo. A consoante " $M$ " refere-se às mães participantes, variando de entrevistada M1 a M14.

As falas das participantes foram transcritas na íntegra em papel A4 e a análise foi baseada na teoria das Representações Sociais e seguiu o modelo de análise de conteúdo de Bardin (2008), sendo um conjunto de instrumentos metodológicos sutis em constante aperfeiçoamento que se aplicam a discursos diversificados, descrevendo e categorizando as análises do conteúdo da entrevista (Bardin, 2008). Por fim, para concretização e organização das análises das categorias encontradas nas entrevistas, primeiro são apresentados os dados sociodemográficos das participantes e, em seguida, os resultados das reflexões e interpretações quanto às informações coletadas, organizadas em quatro categorias: Representações sociais da maternidade; Expectativa da gravidez; Sentimentos da descoberta; e Dificuldades encontradas.

\section{Resultado e Discussão}

\section{Dados Sociodemográficos das Participantes}

Neste primeiro tópico, consideram-se os dados sociodemográficos da pesquisa (Tabela 1). Em seguida, foram classificados e analisados os discursos da entrevista por meio de alguns temas e de acordo com o significado do que foi proposto (Tabela 2).

Na tabela 1, são apresentados os dados sociodemográficos das entrevistadas da pesquisa. Nesse sentido, com intuito de conhecer melhor o perfil e a realidade das participantes da pesquisa, algumas perguntas foram realizadas, como estado civil, grau de instrução, 
profissão, renda familiar, se possui benefício socioassistencial e o tipo de deficiência física ou intelectual do filho/a.

Observa-se que, considerando o estado civil das 14 participantes, seis estão em união estável, duas separadas, três casadas e três solteiras. Destaca-se que a maioria das entrevistadas estão em união estável, porém a maioria das participantes não vivem mais com os pais dos filhos/as com deficiência. Os pais das crianças, em sua maioria, ao descobrir a responsabilidade que é cuidar de um filho/a com deficiência abandonam a parceira, deixando os cuidados e responsabilidades para as mães.

Quanto ao grau de instrução das 14 entrevistadas, quatro têm o Ensino Médio Completo, seis o Ensino Fundamental Incompleto, uma o Ensino Fundamental Completo, uma tem Curso Superior Completo e duas não são alfabetizadas. Percebe-se que há uma predominância de pessoas que não terminaram de concluir o ensino fundamental;

Entre as principais atividades desenvolvidas pelas entrevistadas, estão: comerciantes (duas), professora (uma), trabalhadora rural (uma), cabeleireira (uma) e dona de casa (nove). Destaca-se que a maioria das participantes é dona de casa, tendo em vista que não é possível trabalhar fora devido os cuidados com o filho/a com deficiência. Dessa forma, as mulheres, em sua maioria, abandonaram o emprego e passaram a fazer as tarefas domésticas como forma de cuidar melhor e se dedicar integralmente à criança.

No que se refere à renda familiar, os resultados apresentam que seis mães recebem um salário mínimo, quatro, dois salários mínimos, duas, três salários mínimos e apenas uma mãe recebe menos de um salário. Tendo em vista que a maior parte das participantes recebe benefício socioassistencial (nove das 14 entrevistadas), elas vivem somente do benefício, o que revela que a maioria das entrevistadas é de baixa renda.

Por último, observa-se que sete das 14 entrevistadas possuem filho/a com deficiência intelectual, duas deficiências físicas e cinco deficiências físicas e intelectuais. Como o foco da entrevista foi sobre as Representações Sociais das mães, não foi especificado os tipos de deficiência dos/as filhos/as.

Tabela 1

Dados sociodemográficos das participantes

\begin{tabular}{|c|c|c|c|c|c|c|}
\hline Mães & $\begin{array}{c}\text { Estado } \\
\text { Civil }\end{array}$ & Grau de Instrução & Trabalho & Renda & $\begin{array}{c}\text { Benefício } \\
\text { Socioassistencial }\end{array}$ & $\begin{array}{l}\text { Deficiência } \\
\text { da Criança }\end{array}$ \\
\hline M1 & $\begin{array}{l}\text { União } \\
\text { Estável }\end{array}$ & $\begin{array}{l}\text { Ensino Médio } \\
\text { Completo }\end{array}$ & Dona de Casa & $\begin{array}{l}\text { Um Salário Mí- } \\
\text { nimo }\end{array}$ & Não & Intelectual \\
\hline M2 & Separada & $\begin{array}{c}\text { Ensino Médio } \\
\text { Completo }\end{array}$ & Dona de Casa & $\begin{array}{c}\text { Um Salário Mí- } \\
\text { nimo }\end{array}$ & Sim & $\begin{array}{c}\text { Física e } \\
\text { Intelectual }\end{array}$ \\
\hline M3 & Casada & \begin{tabular}{|c|}
$\begin{array}{c}\text { Ensino Médio } \\
\text { Completo }\end{array}$ \\
\end{tabular} & Cabeleireira & $\begin{array}{c}\text { Dois Salários } \\
\text { Mínimos }\end{array}$ & Não & Intelectual \\
\hline M4 & Solteira & $\begin{array}{c}\text { Ensino Fundamen- } \\
\text { tal Incompleto }\end{array}$ & $\begin{array}{c}\text { Trabalhadora } \\
\text { Rural }\end{array}$ & $\begin{array}{c}\text { Dois Salários } \\
\text { Mínimos }\end{array}$ & Sim & Intelectual \\
\hline M5 & Solteira & $\begin{array}{c}\text { Ensino Fundamen- } \\
\text { tal Completo }\end{array}$ & Comerciante & $\begin{array}{c}\text { Três Salários Mí- } \\
\text { nimos ou Mais }\end{array}$ & Sim & $\begin{array}{c}\text { Física e } \\
\text { Intelectual }\end{array}$ \\
\hline M6 & $\begin{array}{l}\text { União } \\
\text { Estável }\end{array}$ & $\begin{array}{c}\text { Ensino Fundamen- } \\
\text { tal Incompleto }\end{array}$ & Dona de Casa & $\begin{array}{c}\text { Um Salário Mí- } \\
\text { nimo }\end{array}$ & Sim & Física \\
\hline
\end{tabular}




\begin{tabular}{|c|c|c|c|c|c|c|}
\hline Mães & $\begin{array}{c}\text { Estado } \\
\text { Civil }\end{array}$ & Grau de Instrução & Trabalho & Renda & $\begin{array}{c}\text { Benefício } \\
\text { Socioassistencial }\end{array}$ & $\begin{array}{l}\text { Deficiência } \\
\text { da Criança }\end{array}$ \\
\hline M7 & Solteira & $\begin{array}{c}\text { Ensino Fundamen- } \\
\text { tal Incompleto }\end{array}$ & Dona de Casa & $\begin{array}{l}\text { Um Salário Mí- } \\
\text { nimo }\end{array}$ & Sim & $\begin{array}{c}\text { Física e } \\
\text { Intelectual }\end{array}$ \\
\hline M8 & $\begin{array}{l}\text { União } \\
\text { Estável }\end{array}$ & $\begin{array}{c}\text { Curso Superior } \\
\text { Completo }\end{array}$ & Professora & $\begin{array}{c}\text { Três Salários Mí- } \\
\text { nimos ou Mais }\end{array}$ & Não & Física \\
\hline M9 & $\begin{array}{l}\text { União } \\
\text { Estável }\end{array}$ & $\begin{array}{c}\text { Ensino Fundamen- } \\
\text { tal Incompleto }\end{array}$ & Dona de Casa & $\begin{array}{c}\text { Um Salário Mí- } \\
\text { nimo }\end{array}$ & $\operatorname{Sim}$ & Intelectual \\
\hline M10 & Casada & Não Alfabetizada & Dona de Casa & $\begin{array}{c}\text { Um Salário Mí- } \\
\text { nimo }\end{array}$ & Sim & Intelectual \\
\hline M11 & $\begin{array}{l}\text { União } \\
\text { Estável }\end{array}$ & $\begin{array}{c}\text { Ensino Fundamen- } \\
\text { tal Incompleto }\end{array}$ & Dona de Casa & $\begin{array}{c}\text { Um Salário Mí- } \\
\text { nimo }\end{array}$ & Sim & $\begin{array}{c}\text { Física e } \\
\text { Intelectual }\end{array}$ \\
\hline M12 & $\begin{array}{l}\text { União } \\
\text { Estável }\end{array}$ & Não Alfabetizada & Dona de Casa & $\begin{array}{c}\text { Dois Salários } \\
\text { Mínimos }\end{array}$ & Sim & Intelectual \\
\hline M13 & Casada & $\begin{array}{c}\text { Ensino Médio } \\
\text { Completo }\end{array}$ & Comerciante & $\begin{array}{c}\text { Dois Salários } \\
\text { Mínimos }\end{array}$ & Não & Intelectual \\
\hline M14 & Separada & $\begin{array}{c}\text { Ensino Fundamen- } \\
\text { tal Incompleto }\end{array}$ & Dona de Casa & $\begin{array}{l}\text { Menos de Um } \\
\text { Salário Mínimo }\end{array}$ & Não & $\begin{array}{c}\text { Física e } \\
\text { Intelectual }\end{array}$ \\
\hline
\end{tabular}

Tabela 2

Análise dos discursos

\begin{tabular}{|l|l|l|l|}
\hline $\begin{array}{c}\text { Representações sociais } \\
\text { da maternidade }\end{array}$ & $\begin{array}{c}\text { Expectativa da } \\
\text { gravidez }\end{array}$ & $\begin{array}{c}\text { Sentimentos da } \\
\text { descoberta }\end{array}$ & \multicolumn{1}{|c|}{ Dificuldades } \\
\hline $\begin{array}{l}\text { Tudo; } \\
\text { Paradoxo; } \\
\text { Responsabilidade; }\end{array}$ & Filho ideal & $\begin{array}{l}\text { Tristeza; } \\
\text { Medo; } \\
\text { Choque }\end{array}$ & $\begin{array}{l}\text { Tratamento; } \\
\text { Preconceito; } \\
\text { Dedicação em tempo integral; } \\
\text { Locomoção; } \\
\text { Financeira }\end{array}$ \\
\hline
\end{tabular}

\section{Representações Sociais da Maternidade}

As Representações Sociais concebem "algo" que forma "universos de opiniões", que são quanto a classes, grupos e cultura (Jovchelovitch, 2007). A partir disso, foi perguntado para as participantes sobre o significado do ser mãe para elas, para compreender como as entrevistadas da pesquisa imprimem o significado da maternidade, associando a algo positivo como "tudo", a "responsabilidade" ao trazer a questão da deficiência e a um "paradoxo" quando se contradizem.

As Representações Sociais que versam sobre a maternidade apareceram cinco vezes relacionada a "tudo". Ressaltando aqui apenas um dos cinco depoimentos:

Ser mãe é tudo na vida, sou louca pelos meus filhos, mais ainda pelo especial. Sempre sonhei em ser mãe e, quando casei, queria logo ser mãe, graças a Deus tenho minhas duas bênçãos. (M11)

Nessas falas, pode-se analisar que, para as mães entrevistadas, a maternidade refere-se ao que se tem de mais importante na vida, sendo tratada como algo fundamental, como um 
processo natural de toda mulher, de modo que, quando a entrevistada M11 diz que a maternidade foi algo que sempre sonhou, já é logo associado a uma idealização, considerando a maternidade como o auge de toda mulher.

Como afirmam os estudos de Rodriguez e Féres-Carneiro (2013), Gomes, Donelli, Piccinini, e Lopes (2008), enquanto para algumas mulheres a maternidade não representa o auge da vida, devido às mudança de prioridades que podem ocorrer com a chegada de um bebê, para outras a maternidade é o processo de realização plena e sonhada por toda mulher, que vem da noção de que a mulher por natureza destina-se à maternidade.

Conforme Scavone (2001), há uma expectativa social sobre a mulher para o processo da maternidade. A sociedade impõe o papel de mãe por vocação, atribuindo a algo. Acreditase, dessa forma, que toda mulher deseja ter filhos/as, pois inicialmente o seu papel era casar e reproduzir, ao passo que uma mulher que não idealizasse ter filhos/as ou cumprir os padrões de dona de casa, era tida como uma péssima mãe.

A representação da maternidade também é encontrada nos discursos das entrevistadas cinco vezes como "paradoxo", quando inicialmente consideram a maternidade de um filho/a com deficiência como algo positivo e, em seguida, se contradizem ao trazer como negativo e suas dificuldades. Como é mostrado nesses três relatos:

Ser mãe é bom demais. No começo foi complicado, mas depois vai se acostumando, principalmente quando é um filho especial, porque você leva um choque, mas acostuma e aprende a amar. (M5)

É tudo, muito bom. . Mas, no início foi muito difícil porque é uma fase de adaptação. Antes a gente não tinha nem noção do que era a doença. (M7)

É bom. Mas, ser mãe de filho com deficiência também é complicado. (M10)

Pode-se perceber nessas afirmações que a maternidade é um paradoxo, ou seja, uma contradição, pois, ao mesmo tempo em que relatam a maternidade como algo bom, citam também os obstáculos enfrentados nesse processo de adaptação, mudando suas concepções quando se pensa em um filho/a com deficiência. Porém, mesmo com essas dificuldades, as mães não deixam de descrever a maternidade a partir de uma perspectiva positiva. Uma hipótese desse paradoxo é o fato de a sociedade esperar que as mulheres tenham uma visão positiva da maternidade, pois, se apresentarem uma perspectiva negativa, podem ser consideradas "mães ruins". Dessa forma, levando em consideração essa exigência social, estes podem ser fatores que influenciaram as representações que as mães têm sobre a maternidade, confirmando e, ao mesmo tempo, contradizendo o que se espera socialmente.

Esses mesmos resultados foram apresentados no estudo de Rodrigues, Rodrigues, Silva, Jorge, e Vasconcelos (2009), abordando que a representação de maternidade para algumas mães é repleta de diversos sentimentos contraditórios, pois, ao mesmo tempo que consideram algo bom, não deixam de destacar as dificuldades da maternidade e as mudanças nos vários aspectos de vida, fato esse que se torna mais evidente no caso de mães de filhos/as com deficiência.

Nesse sentido, a sociedade estabelece que, para ser considerada uma "boa mãe", é indispensável compreender a maternidade apenas por aspectos positivos, desconsiderando os aspectos ruins, sendo necessário se sacrificarem nos cuidados com os/as filhos/as. Além dis- 
so, devem permanecer satisfeitas com as tarefas maternas. Para tanto, é possível perceber a necessidade de desconstruir esse mito de mãe perfeita que pode gerar sofrimento, pelo fato da cobrança social, não considerando "mães ideais" aquelas que não estejam dentro dos padrões simplesmente por relevarem aspectos reais da maternidade (Azevedo \& Arrais, 2006).

Na entrevista, a maternidade também aparece associada como uma "responsabilidade" para as mães. Isso foi constatado quatro vezes nos relatos das participantes, como mostram esses dois relatos:

Em termos gerais, ser mãe eu encaro como uma responsabilidade, que você assume desde o dia que você descobre que está grávida, e eu acho que é para sempre. Acho que é você cuidar do outro, ter amor por esse outro, é se responsabilizar pela educação desse outro, é um compromisso. Então acho que a maternidade está associada não só à questão do amor, mas à responsabilidade, porque o amor e a responsabilidade andam juntas. (M8)

[. . .] É uma dedicação e responsabilidade que devemos ter sempre com nossos filhos. (M12)

Verifica-se que as mães assumem a maternidade como um compromisso que elas têm com os/as filhos/as, tomando para si o dever de cuidar e dedicar sua vida a criança. Nota-se, em um dos relatos (M8), que a maternidade não se resume apenas em amar o/a filho/a, mas em ser responsável pela educação destes e se dedicar integralmente.

Para Braga e Amazonas (2005), muitas mães sentem uma sobrecarga de responsabilidade pela vida do/a filho/a, pois denominam a si mesmas uma obrigação sobre os cuidados com a criança, gerando sentimentos bons e ruins diante essa responsabilidade em tempo integral. Em se tratando de um/a filho/a com deficiência, a responsabilidade torna-se aumentada, já que a exigência de cuidado se torna maior.

\section{Expectativa da Gravidez}

O processo de espera de um/a filho/a durante a gravidez já é cercado de expectativas, o que normalmente é idealizado pelo nascimento de uma criança saudável e "perfeita" aos olhos da sociedade, ou melhor, uma criança sem deficiências (Grossi, Crisostomo, \& Souza, 2016). Verifica-se, a partir de treze relatos, que há uma expectativa pelo filho/a ideal, como apontam esses cinco discursos.

Eu imaginava tanta coisa, imaginava uma criança saudável, imaginava o jeito do cabelo, ficava tentando comparar com os outros irmãos, mas não foi nada do que a gente esperava. Não foi uma experiência boa. . . (M7)

Imaginava que não ia nascer com problema. Esperava que fosse nascer saudável. (M9)

Esperava que fosse uma criança saudável, que com 5 anos eu pudesse voltar a ter minha vida normal, voltar a trabalhar, a estudar. Esperava tudo o que uma mãe espera de uma criança normal. (M2)

Esperava que ele fosse uma criança normal igual às outras, pois eu nunca pensei na minha vida em ter um filho especial. (M11) 
Esperava que fosse uma criança normal, perfeita, a gente sempre espera isso. A gente sempre pensa 'que venha homem ou mulher, mas que venha com saúde'. (M5)

Nota-se que as mulheres criam uma expectativa de que seus bebês tenham que nascer saudáveis, normais e perfeitos fortalecendo as crenças que são estabelecidas na sociedade do "filho idealizado" que são aquelas crianças sadias, sem "nenhuma imperfeição", sendo possível constatar que todas as mães entrevistadas não esperavam um filho/a como deficiência. Com isso, percebe-se que as pessoas estão sempre querendo se enquadrar em padrões de normalidade, e, quando as mães percebem que seus filhos/as não estão nesses padrões, isso causa um desconforto, pois o esperado são as "crianças normais e saudáveis" e as crianças tidas como "anormais" são descartadas.

Conforme Prado (2006), as mães no processo de espera de um/a filho/a, projetam sonhos e expectativas sobre a criança, imaginando até as qualidades que as crianças vão adquirir. Porém, quando um bebê nasce com alguma deficiência, as mães precisam lidar com os sentimentos de frustração. Para Bueno, Monteiro, e Souza (2011), há uma necessidade de elaborar o luto de um filho imaginado e aceitar o filho real, sendo que cada família tem sua forma de processar o diagnóstico de uma deficiência, em que, para alguns, esse processo de aceitação do filho/a "irreal" pode ser mais demorado do que para outros/as.

\section{Sentimentos da Descoberta}

A análise das entrevistas explicitou que as mães reagiram intensamente à notícia da deficiência do filho/a. As reações foram em sua maioria simultânea à notícia, mas não seguiram uma ordem pré-estipulada, sendo que uma não excluía necessariamente a outra, como constatado seis vezes nos discursos, em que as mães reagiram com sentimento de tristeza frente à descoberta da deficiência da criança:

Eu fiquei triste demais, chorei. Eu pensava que isso só acontecia com os outros. (M4)

Eu entrei em depressão e passei uns dois anos fazendo terapia. No começo eu escondi ele, não queria que ninguém o visse porque tinha vergonha. Mas hoje para mim ele é uma criança normal. Quando o médico disse que ele tinha um problema meu mundo caiu naquele momento, eu chorei, precisei da ajuda de um psicólogo porque eu não aceitava. (M5)

Não queria acreditar, fiquei triste, eu não queria, 'qual a mãe que não quer um filho saudável?’ Eu me senti culpada por ele ser assim. Eu não queria aceitar. (M9)

Pode-se considerar, a partir dessas afirmações, que a tristeza é um dos sentimentos que são gerados frente ao diagnóstico de um/a filho/a com deficiência, o que é possível observar mais nitidamente nos discursos das entrevistadas M5 e M13, em que essa tristeza causou alguns estados depressivos pelo fato da não aceitação. Contudo esse processo de adaptação e aceitação dependerá da individualidade de cada mãe. Para algumas, esse sentimento de tristeza não é muito duradouro, pois essas se adaptam rápido com o impacto do diagnóstico do/a filho/a; porém, para outras, esse processo de adaptação pode ser demorado.

Conforme Brunhara e Petean (1999, p. 34), "a tristeza é um aspecto revelador da magia ou aflição", seu estudo aponta que, no momento da notícia, as mães também revelam tris- 
teza, decepção e frustração frente à ausência da satisfação e desejo do filho/a idealizado/a. Além disso, as mulheres lamentam as mudanças que estão precisando fazer na sua vida e podem apresentar uma "tristeza crônica", que traz à tona a diferença e o que poderia ser e não é, sendo este um sentimento que nunca é superado e frequentemente revivido: momento de entrada na escola, aniversários etc.

Duas entrevistadas também citaram em seus relatos sentimento de medo. Como podemos observar nesse relato:

Só surpresa. Eu descobrir quando ela nasceu e aí sim houve uma surpresa, um medo, um receio, uma dúvida foi algo que me atemorizou, me fragilizou. . . Era tudo muito novo. . . Meses depois eu ainda convivi com sentimentos de tristeza, de receio, de medo de como seria, qual seria a recepção das outras pessoas, porque no caso da minha filha, a diferença é muito visível. Mas eu pensei que todos nós somos limitados, independente da cor, da deficiência ou não. Meu medo era com relação as dificuldades externas, como dificuldades econômicas, sociais, principalmente o meio social era o que me atemoriza$v a$, as condições que ainda não temos de lidar com a diferença. (M8)

Outro sentimento frente ao diagnóstico é o medo, do/a filho/a não ser aceito/a socialmente e de sofrer devido a consequências de uma sociedade que não sabe respeitar as diferenças, criando nas mães um medo de um futuro ainda incerto para seu/sua filho/a. Esse resultado também foi demonstrado no estudo de Lazzarotto e Schmidt (2013). Segundo eles, as mães abordam o medo e preocupação com o futuro dos filhos/as com deficiência, do olhar da sociedade, da recepção das pessoas, da independência pelo fato desses filhos/ as serem relativamente dependentes. Nesse sentido, sentem-se insegurança e medo do seu papel de cuidado, não se sentindo preparadas para o enfrentamento da condição clínica dessas crianças.

Outro sentimento citado por quarto mães, foi um estado de choque frente à descoberta de um filho/a com deficiência:

Foi e ainda é um choque para nós. Eu sempre percebi o comportamento dele anormal. Quando recebi o diagnóstico fiquei um pouco com medo, tenebrosa, porque a gente nunca aceita esse tipo de coisa logo de primeira. (M3)

Foi um choque muito grande, na hora da notícia eu não sabia nem voltar para casa. Quando eu estava grávida a gente já pensava que ela não ia sobreviver. Foi muito triste....

O impacto foi muito grande, fiquei sem chão, passei muitos dias sem saber o que fazer da minha vida. ... (M11)

Nos relatos acima, fica claro como as mães sofrem um grande choque diante o diagnóstico do/a filho/a, por ser algo que não é esperado, sendo possível detectar o impacto dessa notícia, pois o processo de descoberta é doloroso até a aceitação do diagnóstico. Conforme Oliveira e Poletto (2015, p. 111), o choque pode ser caracterizado como "uma interrupção abrupta dos estados emocionais usuais, que rompe com o equilíbrio de cada um". Sendo um abalo emocional, descrito como uma sensação de impotência, situação de torpor e sentimentos de desamparo. 
Qualquer dúvida levantada em relação às condições de saúde física e/ou mental do fiIho/a deixam as mães chocadas e, muitas vezes, sem saber como proceder no momento da notícia. Essa reação é aliada a sentimentos de pesar e de perda. Pesar pelo próprio desapontamentos e perda da criança sonhada. Contudo Oliveira e Poletto (2015) destacam que, apesar do diagnóstico provocar um momento inicial de choque nas mães e familiares, com resposta de grande impacto, pela vontade que a criança seja "normal", ocorre também um processo de aceitação e adaptação, acontecendo em várias etapas, com intensidades e tempos variados:

... mas logo na maternidade quando eu descobrir que ela era uma criança especial eu fiz uma reflexão de imediato de pensar 'se eu agora não amá-la como é que as outras pessoas irão amá-la?' naquele momento em tomei uma decisão. . . (M8).

... se fosse para passar novamente eu passaria tudo de novo para eu ter ela, não me arrependo momento nenhum de ter persistido com a gravidez porque minha filha é um sonho, qualquer mãe queria ter ela, não é porque é minha, mas é a coisa mais linda. (M7).

... Ao receber a notícia fiquei muito triste, depressiva, somente depois de algum tempo com tratamento psicológico que eu percebi que ter uma criança especial não é tão difícil como imagina no início. Eaos poucos me adaptei com diagnóstico do meu filho. (M13)

\section{Dificuldades Encontradas}

Constata-se que o nascimento de uma criança com deficiência ocasiona desafios para as mães. As dificuldades vivenciadas por elas são inúmeras, como o cuidado árduo, bem como o preconceito da sociedade e tantos outros desafios experimentados por essa mãe e toda família (Guerra et al., 2015). Pode-se observar, a partir das entrevistas realizadas, que as principais dificuldades encontradas pelas mães estão relacionadas a "tratamento", "preconceito", "dedicação em tempo integral", "locomoção" e "dificuldades financeiras".

As dificuldades no tratamento são apresentadas sete vezes nos discursos das mães entrevistadas, como apontam essas três falas:

Muitas dificuldades, principalmente porque a gente precisa levar no médico e não tem, precisa levar no Psicólogo, corro atrás e não acho. Para achar uma consulta pública é um problema. Quando ele estava indo no Psicólogo estava melhor. (M1)

Umas das dificuldades é com a saúde dele, com relação a cirurgia que demora bastante. Eu tinha que ir para fora para fazer as cirurgias porque aqui é dificil, a cadeira de rodas, por exemplo, foi muito difícil para eu conseguir, carreguei ele no colo até bem grande. (M2)

Eu acho difícil conseguir acompanhamento com os médicos. A maior dificuldade é conseguir um local especifico para fazer acompanhamento. (M7)

A partir do conteúdo dos discursos das entrevistadas, constata-se que existe uma grande dificuldade na busca de tratamento médico e psicológico para os/as filhos/as, o que se confirma nos relatos das entrevistadas M1 e M7, ao expressarem uma crítica aos serviços público oferecidos. Já na narrativa de M2 é apontado a demora desses atendimentos forne- 
cidos. Nota-se uma necessidade de mudança nos tratamentos oferecidos, sendo fundamentais mais investimento nos serviços de saúde para garantir uma qualidade de vida para essa criança e sua família.

O estudo de Cerqueira, Alves, e Aguiar (2016) mostra que as mães de crianças com deficiência deparam-se com obstáculos em lidar com o problema de saúde dos/as filhos/as, pois este demanda cuidados contínuos e necessita de idas e vindas constantes em instituição de saúde, de educação e de assistência social, sendo que, muitas vezes, esses serviços não são oferecidos ou levam bastante tempo. Nesse sentido, os autores destacam a importância de desenvolver políticas direcionadas para pessoas com deficiência, para que seja possível melhorar os serviços de saúde fornecidos, produzindo assim respostas mais efetivas, a depender da demanda da criança.

O preconceito também é um das dificuldades encontradas pelas mães que têm filhos/as com deficiência, sendo visto cinco vezes nos relatos das mães.

A sociedade é o maior peso para mim, porque tem coisas que ofende muito, principalmente a rejeição. (M3)

Ele já passou por muito preconceito. Na outra escola chamavam ele de doido e eu ficava muito triste. (M4)

No começo sentir preconceito das outras pessoas, principalmente da família, eles olhavam para meu filho de um jeito diferente. (M5)

As pessoas quando vê ele pela primeira vez levam um susto, tem gente que tem preconceito e a gente percebe especialmente as mães... Alguns ficam olhando e tem crianças que choram com medo do meu filho, ficam agarradas nas mães com medo, mas é tranquilo pois realmente o impacto é grande, foi difícil até para mim quando ele nasceu, imagina para as outras pessoas. (M11)

Nesses relatos, observa-se que o preconceito ainda é existente, que muitas crianças com deficiência sofrem as consequências de uma sociedade que discrimina o outro devido a não aceitar o que é tido como diferente. Percebe-se, nas falas dessas mães, que esse preconceito está desde o ambiente escolar até no âmbito da própria família. Constata-se que a sociedade enquadra as pessoas em normalidade, de forma que, os que não entrarem nesses padrões são tidos como "anormais", sendo assim excluídos/as (Bastos \& Deslandes, 2008; Pintanel, Gomes, \& Xavier, 2013).

Estudos apontam que, dentre os inúmeros empecilhos encontrados pelas mães de fiIhos/as com deficiência, destaca-se a inserção social, pois são muitos desafios que impossibilita essa inserção, tais como o preconceito. Desmistificar a compreensão que a sociedade tem sobre a deficiência promove o respeito às diferenças e diminui a discriminação. Além disso, discutir essa temática evita uma sociedade que exclui tudo que é diferente, devendo assim, buscar trabalhar a inclusão das pessoas com deficiência em todos os âmbitos sociais (Batista \& França, 2007; Monteiro, Matos, \& Coelho, 2004; Grossi, Crisostomo, \& Souza, 2016).

Em quatro discursos, as mães entrevistas citaram a dedicação em tempo integral como uma das maiores dificuldades: 
A questão do tempo é o fator principal, porque demanda um tempo e um trabalho diferente. Você precisa trabalhar fora, precisa dar atenção ao seu filho, leva-lo a médicos, especialistas. Depois da questão do meio social, de lidar com os outros, a maior dificuldade é o tempo, a demanda de trabalho fora. (M8)

As dificuldades do cuidado é que exige meu tempo todo, pois vivo 24 horas para ele, até de noite preciso ficar ol hando ele para ver se ele ta bem, pois pode ter crise de convulsão eu não perceber, por isso que ele dorme no meu quarto próximo a minha cama, aí eu fico acordando a noite inteira olhando ele e virando para um lado e outro. (M11)

A maioria das participantes abandonaram sua vida profissional para se dedicar por completo à criança. Outras mães assumem papel de pai e mãe, ocorrendo uma maior sobrecarga. Essas respostas foram também encontradas no estudo de Smeha e Cezar (2011), a partir de uma entrevista realizada com mães de crianças com diagnóstico de autismo, em que foi possível verificar que várias mães se dedicam em tempo integral aos filhos/as, abdicando das suas próprias prioridades, vida profissional e social, para assumir as responsabilidade maternas, adequando assim suas rotinas em função do/a filho/a; algumas necessitam alterar a dinâmica do funcionamento da família mediante o nascimento de uma criança com alguma deficiência.

Deve-se destacar que é sobre as mães que recaem os maiores cuidados com o/a filho/a com deficiência, gerando-Ihes uma sobrecarga. E, em muitos casos, não obtêm auxílio necessário dos familiares e assumem as principais responsabilidades sobre os cuidados. Isso se deve a uma construção social de se atribuir à mulher o dever de criar os/as filhos/as, ocasionando uma má divisão dos papéis sociais (Silva, 2011; Viera et al., 2008; Grossi, Crisostomo, \& Souza, 2016).

As mães retratam também uma dificuldade de locomover-se com um/a filho/a com deficiência, sendo isso demonstrado cinco vezes nos discursos:

Me locomover com ele é difícil. Às vezes eu me vejo fraca e ao mesmo tempo forte, porque ele já está com oito anos e eu achei que não fosse chegar até aqui. Quando ele nasceu, eu pensei: 'meu Deus como vou lidar com uma criança com paralisia, como é que vai ser?', mas hoje estou aqui e estou forte. A estrutura da cidade também é péssima, o elevador do ônibus não funciona, tenho que levar no braço mesmo. . . (M2)

Locomoção, pois as ruas são estragadas, sendo que são poucas calçadas para cadeirantes, tudo tem dificuldade. (M11)

Fica evidenciado o inconformismo em relação à estrutura da cidade. Além disso, deve-se destacar a fala de M2 que faz uma crítica à falta de elevadores para pessoas com deficiência nos transportes públicos da cidade, precisando carregar seu filho/a no colo. Salienta-se que a deficiência, seja ela física ou intelectual, possibilita vários obstáculos a serem enfrentados, sendo que uma das principais dificuldades quando se refere a uma deficiência física é a locomoção no seu cotidiano, pois há inúmeros empecilhos a essa locomoção, tais como a falta de rampas e calçadas para pessoas com deficiência e, quando existem, muitos não respeitam. Outro problema está relacionado à falta de compreensão de motoristas de transportes públicos e da própria população, pois alguns não se sensibilizam quando veem as dificuldades das mães em carregar o/a filho/a ao colo, por isso que há uma necessidade de melhorar 
as estratégias que facilitem a locomoção dessas mães com seus/suas filhos/as, investindo em políticas públicas eficazes (Pereira, Caribé, Guimarães, \& Matsuda, 2011; Oliveira et al., 2008).

Outro problema enfrentado pelas mães é a dificuldade financeira, sendo isso mencionado quatro vezes pelas entrevistadas.

Encontrei muitas dificuldades, por que quando descobrir logo me separei do pai dele e para criar esse menino com problema só com o dinheiro da bolsa escola foi muito difícil. Então não tinha dinheiro para comprar os remédios para ele. (M4)

Dificuldade para cuidar e sustentar financeiramente pois logo que meu filho nasceu o pai da criança me abandonou e desde lá eu cuido do meu filho sozinha, e são muitos gastos com remédios e idas no hospital. (M14)

Ao receberem o diagnóstico da criança, algumas mulheres são abandonadas pelos seus companheiros, assumindo sozinhas a responsabilidade de criar e sustentar financeiramente os/as filhos/as. Assim precisaram lidar com os gastos com remédios e tratamento do/a filho/a, considerando que a maioria das mães da pesquisa não tem condições financeiras favorecidas, mantendo-se com os auxílios oferecidos, pois algumas são impossibilitadas de trabalhar para dedicar-se aos cuidados da criança.

Resultados parecidos também foram encontrados na pesquisa de Oliveira et al. (2008) com cuidadoras de crianças com paralisia cerebral, que identificaram a dificuldade financeira como um fator que causa danos no processo de cuidar da criança, pois são caros os medicamentos, alimentação adequada e, muitas vezes, a renda mensal não é suficiente para tais demandas. Destaca ainda que algumas mães não conseguem conciliar o trabalho fora de casa e os cuidados com o/a filho/a, assim o recurso financeiro torna-se responsabilidade do pai quando este é presente, sendo que para essas mães o que proporcionaria uma vida estável seria se tivessem segurança financeira.

\section{Conclusões}

Um dos aspectos que é constatado nesta pesquisa é o fato de a gravidez ser cercada de expectativas de um/a filho/a ideal. Pode-se observar, diante os relatos das entrevistadas, que nenhuma mãe esperava um/a filho/a com deficiência. Com isso, nota-se que socialmente espera-se um/a filho/a saudável e sem imperfeições, devido a tudo que sai dos padrões de normalidade ser discriminado, causando comportamentos e sentimentos disfuncionais ao lidar com um diagnóstico de uma deficiência. Identificou-se, ainda, que o processo de aceitação é vivenciado de forma diferente devido a subjetividade e representação de cada mãe, como foi constatado nos relatos de algumas entrevistadas, para quem este pode ser um momento muito difícil, porém, para outras, o processo de adaptação e aceitação pode ocorrer mais rapidamente.

Fica evidente que a descoberta do diagnóstico de uma criança com deficiência pode ocasionar frustrações e sentimentos negativos; por isso, torna-se fundamental o papel do/a psicólogo/a para acolher essas mães e os demais familiares para que ocorra o processo de aceitação da deficiência do/a filho/a. É necessário, pois, oferecer um suporte psicológico para essas mães, possibilitando-Ihes lidar com as dificuldades encontradas logo após o diagnóstico. 
Portanto seria oportuna a realização de estudos abordando essa temática, possibilitando pensar em estratégias de intervenções a fim de diminuir o preconceito existente e promover uma qualidade de vida para essas mães e os/as filhos/as com deficiência, além de permitir uma melhor compreensão sobre a maternidade, para que seja possível desenvolver medidas que lhes ajudem enfrentar os obstáculos encontrados na sociedade.

Destaca-se também a importância da Psicologia em oferecer oportunidades para o desenvolvimento integral da criança com deficiência, mediante seus aspectos cognitivos, psicossocial, físico e afetivo, auxiliando as famílias a desenvolverem capacidades pessoais para proporcionar que o/a filho/a cresça com autonomia, afeto e segurança, reconhecendo seus potenciais, inserindo-os nas relações sociais, na escola, no esporte ou no lazer.

Por fim, salienta-se a necessidade de compreender os valores, crenças e ideias relacionadas ao filho/a idealizado/a pelas mães na maternidade, podendo, dessa forma, intervir precocemente e entender os sentimentos e comportamentos resultantes da descoberta da criança com deficiência. Ressalta-se que as representações sociais influenciam no modo de viver e cuidar de um/a filho/a com deficiência, no entanto deve-se considerar que cada pessoa é única no modo de agir e de sentir.

\section{Referências}

Almeida, M. I. M. A. (1987). Nova maternidade: Uma ilustração das ambiguidades do processo de modernização da família. In S. A. Figueira (Org.), Uma nova família? (pp. 55-68). Rio de Janeiro: Jorge Zahar.

Amiralian, M. L. T. M. (2003). Deficiências: Um novo olhar. Contribuições a partir da psicanálise winicottiana. Estilos da Clínica, 8(15), 99-111.

Azevedo, K. R., \& Arrais, A. R. (2006). O mito da mãe exclusiva e seu impacto na depressão pós-parto. Psicologia: Reflexão e Crítica, 19(2), 269-276.

Bardin, L. (2008). Análise de conteúdo. Lisboa: Edições 70.

Bastos, O. M., \& Deslandes, S. F. (2008). A experiência de ter um filho com deficiência mental: Narrativas de mães. Cadernos de Saúde Pública, 24(9), 2141-2150.

Batista, S. M., \& França, R. M. (2007). Família de pessoas com deficiência desafios e superação. Revista de Divulgação Técnico-Científica do ICPG, 3(10), 1807-2836.

Begossi, J. (2003). O luto do filho perfeito: Um estudo psicológico sobre os sentimentos vivenciados por mães com filhos portadores de paralisia cerebral (Dissertação de Mestrado, Universidade Católica Dom Bosco, Campo Grande, MS, Brasil).

Braga, M. G. R., \& Amazonas, M. C. L. (2005). Família: Maternidade e procriação assistida. Psicologia em Estudo, 10(1), 11-18.

Brunhara, F., \& Petean, E. B. L. (1999). Mães e filho especiais: Reações, sentimentos e explicações à deficiência da criança. Revista Paidéia, 9(16), 31-40.

Bueno, R. K., Monteiro, M. A., \& Souza, S. A. (2011). Equoterapia: Do filho idealizado para o filho real. Vivências: Revista Eletrônica de Extensão da URI, 7(13), 101-107.

Cerqueira, M. M. F., Alves, R. O., \& Aguiar, M. G. G. (2016). Experiências vividas por mães de crianças com deficiência intelectual nos itinerários terapêuticos. Ciência \& Saúde Coletiva, 21(10), 3223-3232.

Cervo, A. L., \& Bervian, P. A. (2002). Metodologia científica (5a ed.). São Paulo: Pearson Prentice Hall. 
Coutinho, S. M. S., \& Menandro, P. R. M. (2009). A dona de tudo: Um estudo intergeracional sobre representações sociais de mãe e esposa. Vitória, ES: Editora GM, PPGP-UFES e Editora Facastelo.

Farr, R. M. (1995). Representações sociais: A teoria e sua história. In P. Guareschi, \& S. Jovchelovitch (Orgs.), Textos em representações sociais. Petrópolis, RJ: Vozes.

Ferreira, D. S., Neves, A. L. M., Siqueira, T. B., \& Barbosa, I. P. B. (2013). Teoria das representações sociais e pesquisa socioeducativa em saúde do idoso: Contribuições teórico-metodológicas. Scientia Amazonia, 2(2), 42-49.

Gomes, A. G., Donelli, T. M. S., Piccinini, C. A., \& Lopes, R. C. S. (2008). Maternidade em idade avançada: Aspectos teóricos e empíricos. Interação em Psicologia, 12(1), 99-106.

Grossi, F. R. S., Crisostomo, K. N., \& Souza, R. S. (2016). Vivências de mães de filhos/as com deficiência: Uma revisão sistemática. Revista das Ciências da Saúde do Oeste Baiano - Higia, 1(2), 134-147. Disponível em http://fasb.edu.br/revista/index.php/higia/article/view/139

Guerra, C. S., Dias, M. D., Ferreira Filha, M. O., Andrade, F. B. , Reichert, A. P. S, Araújo, V. S. (2015). Do sonho a realidade: Vivência de mães de filhos com deficiência. Texto Contexto Enfermagem, Florianópolis, 24(2), 459-66.

Jovchelovitch, S. (2007). Vivendo a vida com os outros: Intersubjetividade, espaço público e representações sociais. In P. Guareschi \& S. Jovchelovitch (Orgs.), Textos em representações sociais (9a ed.). Petrópolis, RJ: Vozes.

Lazzarotto, R., \& Schmidt, E. B. (2013). Ser mãe de crianças com paralisia cerebral: Sentimentos e experiências. Revista Perspectiva, 37(140), 61-72.

Maldonado, M. T. (1997). Psicologia da gravidez. Petrópolis, RJ: Vozes.

Milbrath, V. M., Cecagno, D., Soares, D. C., Amestoy, S. C., \& Siqueira, H. C. H. (2008). Ser mulher mãe de uma criança portadora de paralisia cerebral. Acta Paulista de Enfermagem, 21(3), 427-43.

Minayo, M. C. S. (Org.). (1998). Saúde e doença: Um olhar antropológico. Rio de Janeiro: Ed. Fiocruz.

Monteiro, M., Matos, A. P., \& Coelho, R. (2004). Adaptação psicológica de mães cujos filhos apresentam paralisia cerebral - Resultados de um estudo. Revista Portuguesa de Psicossomática, 6(1), 115-130.

Moscovici, S. (2007). Representações sociais: Investigações em psicologia social (6a ed., P. A. Guareschi, trad.). Petrópolis, RJ: Vozes.

Oliveira, M. F. S., Silva, M. B. M., Frota, M. A., Pinto, J. M. S., Frota, L. M. C. P., Sá, F. E. (2008). Qualidade de vida do cuidador de criança com paralisia cerebral. RBPS, 21(4), 274-280.

Oliveira, I. G., \& Poletto, M. (2015). Vivências emocionais de mães e pais de filhos com deficiência. Revista da SPAGEST, 16(2), 102-119.

Pereira, L. M. F., Caribé, D., Guimarães, P., \& Matsuda, D. (2011). Acessibilidade e crianças com paralisia cerebral: A visão do cuidador primário. Fisioterapia em Movimento, 24(2), 299-306.

Pintanel, A. C., Gomes, G. C., \& Xavier, D. M. (2013). Mães de crianças com deficiência visual: Dificuldades e facilidades enfrentadas no cuidado. Revista Gaúcha de Enfermagem, 34(2), 86-92.

Prado, L. C. (2006). Entre a realidade e os sonhos: O desafio das famílias com bebês. Porto Alegre: L. C. Prado. 
Richardson, R. J. (1989). Pesquisa social: Métodos e técnicas. São Paulo: Atlas.

Rodrigues, D. P., Rodrigues, F. R. A., Silva, L. M. S., Jorge, M. S. B., \& Vasconcelos, L. D. G.

P. (2009). O adolescer e ser mãe: Representações sociais de puérperas adolescentes. Cogitare Enfermagem, 14(3), 455-462.

Rodriguez, F. T., \& Féres-Carneiro, T. (2013). Maternidade tardia e ambivalência: Algumas reflexões. Tempo Psicanalítico, 45(1), 111-121.

Rolim, L., \& Canavarro. M. C. (2001). Perdas e luto durante a gravidez e puerpério. In M.C. Canavarro (Eds.), Psicologia da gravidez e da maternidade. Coimbra, Portugal: Quarteto Editora.

Sá, C. P. (2004). Representações sociais: o conceito e o estado atual da teoria. In: M. J. Spink (Orgs.), O conhecimento no cotidiano: As representações sociais na perspectiva da psicologia social. São Paulo: Brasiliense.

Scavone, L. (2001). Maternidade: Transformação na família e nas relações de gênero. Interface-Comunicação, Saúde, Educação, 5(8), 47-60.

Smeha, L. N., \& Cezar, P. K. (2011). A vivência da maternidade de mães de crianças com autismo. Psicologia em Estudo, 16(1), 43-50.

Silva, A. M. F. (2011). Representações sociais da família sobre a deficiência física da criança e suas implicações no cotidiano. (Tese de doutorado, Universidade Federal de Santa Catarina, Florianópolis, Brasil).

Souza, L. G. A., \& Boemer, M. R. (2003). O ser-com o filho com deficiência mental alguns desvelamentos. Paidéia, 13(26), 209-219.

Vieira, N. G. B. et al. (2008). O cotidiano de mães com crianças portadoras de paralisia cerebral. Revista Brasileira em Promoção, 21(1), 55-60.

Recebido: 30/07/2017

Última revisão: 18/04/2018

Aceite final: 20/05/2018

\section{Sobre as autoras:}

Kelly Nunes Crisostomo - Graduada em Psicologia pela Faculdade São Francisco de Barreiras (FASB). Psicóloga Clínica e Psicóloga Escolar na Prefeitura de Formosa do Rio Preto, BA. E-mail: kellynunes_knc@hotmail.com.br, Orcid: http://orcid.org/0000-0003-0865-1564

Fabiana Regina da Silva Grossi - Doutoranda em Psicologia e mestre em Psicologia da Saúde pela Pontifícia Universidade Católica de Goiás. Docente da Faculdade São Francisco de Barreiras (FASB). E-mail: fabiana@fasb.edu.br, Orcid: http://orcid.org/0000-0002-9093-2041

Rafaela dos Santos Souza- Pós-Graduação em Trabalho Social com Famílias e Sociedades e graduada em Psicologia pela Faculdade São Francisco de Barreiras (FASB). E-mail: rafaelasouza_s@hotmail.com,

Orcid: http://orcid.org/0000-0002-8044-0174 